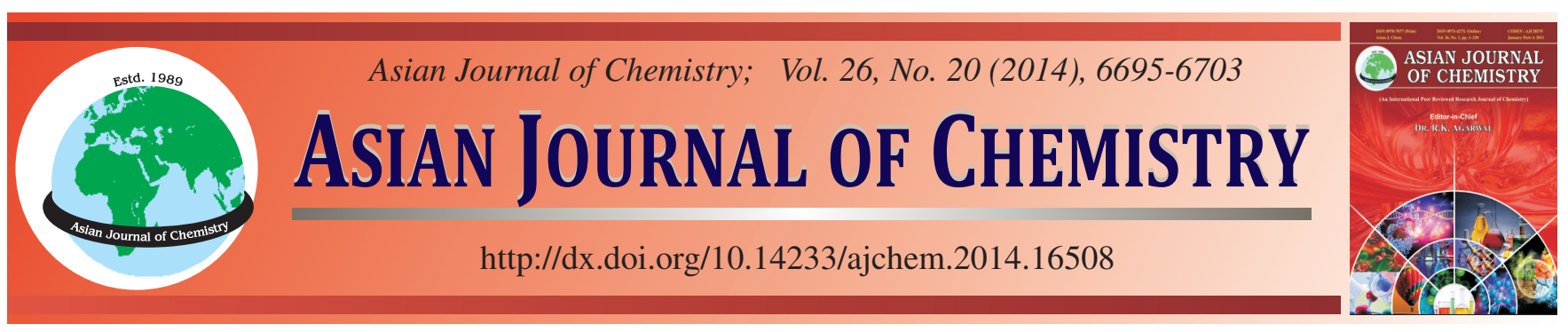

\title{
Impact of Accelerated Weathering Conditions on Morphology and Degradation Kinetics of Polyethylene Carrying Bags
}

\author{
M.J. KHURRAM ${ }^{1,2, *}$, M.K. BALOCH ${ }^{1,3}$ and L.C. SimON ${ }^{2}$
}

${ }^{1}$ Department of Chemistry, Gomal University, Dera Ismail Khan, KPK, Pakistan

${ }^{2}$ Department of Chemical Engineering, University of Waterloo, 200 University Avenue West, Waterloo, Ontario, N2L 3G1, Canada

${ }^{3}$ Present address: Department of Chemistry, University of Sargodha, Sub-Campus Bhakkar, Pakistan

*Corresponding author: Fax: +92 966 750255; Tel: +92 3339969737; E-mail: zebkhurram@yahoo.com

Received: 10 October 2013;

Accepted: 6 March 2014;

Published online: 25 September 2014;

AJC-15993

Though the importance of the production of polyethylene carrying bags could not be denied yet their abundant use, non-biodegradability
and stability against light and heat have created environmental as well as waste management problems. One of the solutions to these
challenges is the recycling of the polymers. Therefore, two samples of commercially available polyethylene carrying bags processed in
Pakistan (Y) and Canada (E) were exposed to accelerated weathering conditions like UV light, heat and condensation processes by
keeping the sample in QUV chamber for 20 days. The analyses were made before, during and after the exposure employing FT-IR, TGA, |
DSC and SEM techniques. The results concluded that after the exposure, the type of the polymer has been changed from HDPE to
LLDPE and LLDPE to LDPE for sample Y and E, respectively. It was observed that the degradation took place due to the formation of
oxygenated products and their rate was increased in term of carbonyl index with the exposure time. The per cent crystallinity was
increased, whereas the activation energy, order of reaction, melting point and thermal stability were decreased with the exposure time in
both the samples. SEM analyses revealed that the degradation was instigated only from the preferential sites in sample Y, while in sample
E the degradation proceeded in all directions. The impact of accelerated weathering conditions was greater on sample E than sample Y
which were discussed and compared in the light of variation in the concentration of additives, molecular weight and poly-dispersity in the
samples.

Keywords: Material testing, Polyethylene carrying bags, Accelerated weathering conditions, Degradation kinetics, Carbonyl index.

ᄂ _ - - - - - - - - - - - - - - - - - - - - - - - - -

\section{INTRODUCTION}

Polyethylene carrying bags have the significant market value due to its light weight, low cost, flexibility, toughness, water resistance, high stability and other several good physical and mechanical properties. Therefore, the production and consumption of the polyethylene have been tremendously increased over the last three decades ${ }^{1,2}$. The industrialists add certain amount of light absorbers, photo and thermal stabilizers to increase the life of the material ${ }^{3-5}$. On the other hand the unwarranted use of such polymer with long life leads to the generation of large quantity of waste. In general, plastic waste is disposed of by land filling and incineration which are not appreciable technologies and is a great concern for the community as it results in the emission of greenhouse gases, dioxins and creation of smoke particles ${ }^{6,7}$. However, recycling of certain polymers like waste bags, food packaging, agricultural mulch films etc. would neither be practical nor economical ${ }^{8}$. To overcome these issues, scientists are trying their level best to find out the ways and means to reuse the polymers in a safer way. One of the techniques in practice is the catalytic degradation of the polymer wastes into fuel oil ${ }^{9,10}$. The technology in vogue for the purpose is very costly as it requires high temperature and appropriate catalyst to guarantee narrow distribution of hydrocarbons ${ }^{11}$. Biodegradation is another attractive route to reduce the waste management but the mechanism is very complex due to the involvement of different oxidative processes caused by the presence of oxygen in the air either by the micro-organisms or by the combination of both ${ }^{12}$. Further to it, most of the waste material is thrown outside and exposed to natural weathering like temperature, UV radiations, moisture contents (humidity, dew, rain) and pollutants (acid rain, aerosols, ozone), depending upon the climatic conditions. Due to the variation in weathering conditions over the surface of the earth, the weathering of plastics is not always an exact science ${ }^{13-15}$. Therefore, to understand the effect of climatic conditions over the plastic stability and to identify the end user of the product, it is need of the day to investigate the 
impact of weathering over the thermal and chemical behaviour of the material. Therefore, the scientists are working hard to understand the impact of weather and weathering conditions over the polymer so the knowledge can be exploited to make good use of the waste. Recent studies concluded that polyethylene can be degraded by photo-oxidation initiated with the formation of polymer radicals due to the breakup of chemical bonds of the polymer chain. The UV radiations (290-320 nm) can provide sufficient energy to dissociate $\mathrm{C}-\mathrm{C}$ and $\mathrm{C}-\mathrm{H}$ bonds and produce free radicals ${ }^{16,17}$. The free radicals formed by the cleavage of bond act as initiator for polymer degradation ${ }^{18}$. The presence of carbonyl groups in degraded polymeric material can be considered as an indicator for the oxidative process which might have taken place during the degradation and make the material vulnerable to further degradation as these groups are photolabile ${ }^{19}$. Recently, it has been studied that the photooxidative degradation of LDPE films can be enhanced by incorporating $\mathrm{Fe}^{3+}$ ions into the polymer and ultimately they will become possibly biodegradable after having their exposure to $\mathrm{UV}$ radiations ${ }^{20}$. Some work is reported over virgin polyethylene samples in this respect and concluded that UV radiations and temperature have quite significant effect in initiation of the degradation processes ${ }^{21}$. In this research work we analyzed processed polyethylene samples which contain several additives in order to get the accurate data instead of analyzing the virgin polyethylene samples. The results obtained will be helpful to understand the impact of accelerated weathering conditions over these samples on molecular level and then to apply this knowledge for the commercial purpose. For this purpose we selected two samples of polyethylene carrying bags which were made and frequently used in Pakistan and Canada which were exposed to Accelerated Weathering Conditions (AWC) using "Accelerated Weathering Tester", QUV chamber. This chamber had the facility to simulate the damaging forces of weather like; UV light, temperature, relative humidity, rain and dew etc. The damaging effects of sunlight in the chamber were simulated by fluorescent UV lamps. The QUV chamber had the ability to produce damage in days or weeks that might have occurred over the months or years of outdoor exposure. To acquire the data needed to understand the mechanism and kinetics of degradation process before, during and after the exposure, DSC, FT-IR, SEM and TGA techniques were employed which are considered to be most relevant in this case ${ }^{22,23}$.

\section{EXPERIMENTAL}

Two samples of polyethylene carrying bags namely, "Special Yaadgar" (Pakistan) and "Econogreen Plastics" (Canada) were used for investigation. These were commercially available and obtained from the local markets of the respective country and abbreviated as "Y" and "E", respectively. The color of sample $\mathrm{Y}$ and $\mathrm{E}$ was light green and black, respectively.

Methods: Following methods were used for the degradation and characterization of polyethylene samples.

Accelerated weathering in QUV chamber: The polyethylene films of both the samples, as received were exposed to accelerated weathering conditions using 'Accelerated Weathering Tester', QUV, manufactured by Q-Panel Company, Cleveland, Ohio. Ten films pieces of each sample were mounted in QUV chamber's sample holder as per instructions provided in its Operating Manual. New fluorescent lamps of UVA-340 type were used in QUV chamber which were 8 in number. The wavelength of the radiations emitted by these UVA-340 lamps was in the range of $315-400 \mathrm{~nm}$. In previous work, scientists used 60 and $65^{\circ} \mathrm{C}$ as back panel temperature of the QUV chamber ${ }^{24,25}$ but we selected temperature of $70{ }^{\circ} \mathrm{C}$ as stated in "cycle B" of ASTM No. D 4329-05. It is reported ${ }^{21}$ and observed that higher temperature deteriorates the material more quickly and expedites the degradation process. This cycle $\mathrm{B}$ includes exposure of UV light to the samples for $8 \mathrm{~h}$ with un-insulated black panel temperature maintained at $70 \pm 3$ ${ }^{\circ} \mathrm{C}$, followed by $4 \mathrm{~h}$ condensation with un-insulated black panel temperature maintained at $50 \pm 3{ }^{\circ} \mathrm{C}$ and then UV exposure. This cycle was repeated for 20 days and the sample was analyzed after the interval of two days of exposure using DSC, FTIR, SEM and TGA techniques.

Estimation of melt flow index: MFI measurement of both the samples was performed by using Dynisco Polymer Test D4001DE machine with $8 \mathrm{~mm}$ die supplied by Alpha Technologies, USA, at $190{ }^{\circ} \mathrm{C}$ using standard weight of $2.16 \mathrm{Kg}$. Rest of the procedure was followed as per ASTM No. D 1238-04c.

Estimation of oxidative induction time and percent crystallinity: For the purpose, DSC Q2000 supplied by TA Instruments, Canada was used and the results obtained were analyzed by using Universal Analysis 2000, TA Instruments, version 4.5A Build in 4.5.0.5 software. OIT for both the samples were measured according to ASTM No. D3895-07.

The per cent crystallinity of the material was also measured by using the same DSC and the samples were heated from 30 to $200{ }^{\circ} \mathrm{C}$ with an increase of $10{ }^{\circ} \mathrm{C} / \mathrm{min}$ and kept at an isothermal mode for $5 \mathrm{~min}$ and then cooled from 200 to $30^{\circ} \mathrm{C}$ with the same rate. All the analyses were carried out under nitrogen atmosphere keeping the flow rate as $50 \mathrm{~mL} / \mathrm{min}$.

FTIR spectroscopy: The FTIR measurements were made over Tensor 27, FTIR spectrophotometer, supplied by Bruker, Germany. The interpretation of the spectra was performed by using software OPUS Version 4.2 Build.

Scanning electron microscopy: Carl Zeiss LEO 1530 scanning electron microscope equipped with Gemini field emission column (FESEM) and EDX/OIM PV9715/69 ME was used. All the samples were dried sputter coated with gold up to the thickness of $10 \mathrm{~nm}$ prior to loading. Argon was used as inert gas during the gold coating. The samples were mounted on the SEM stub with a conductive double-face adhesive tape.

Thermogravimetric analyses: Thermogravimetric analyses were performed using TGA Q500 supplied by TA Instruments, Canada, using platinum pans for the investigations. The temperature was varied from 30 to $650{ }^{\circ} \mathrm{C}$ using $5 ; 10 ; 15 ; 20{ }^{\circ} \mathrm{C} /$ min heating rates. The flow rate of nitrogen gas was kept as $50 \mathrm{~mL} / \mathrm{min}$ to keep the atmosphere inert. The results obtained in this way were analyzed for the determination of kinetic parameters like activation energy $\left(E_{a}\right)$ and order of reaction (n) of the process.

Investigation of degradation kinetics: In general, the decomposition of solid polymer can be associated with the reactions, which may be represented by the processes

$$
\mathrm{A}_{\text {solid }} \rightarrow \mathrm{B}_{\text {solid }}+\mathrm{C}_{\text {gas }}
$$


where $\mathrm{A}$ is the initial, $\mathrm{B}$ is the residue and $\mathrm{C}$ is the gas material. For thermogravimetric analysis, the degree of conversion (decomposition) can be defined as

$$
\alpha=\frac{\left(\mathrm{W}_{\mathrm{o}}-\mathrm{W}_{\mathrm{t}}\right)}{\left(\mathrm{W}_{\mathrm{o}}-\mathrm{W}_{\infty}\right)}
$$

where $\alpha$ is the degree of conversion, $\mathrm{W}_{\mathrm{o}}$ is the initial weight of the sample, $\mathrm{W}_{\mathrm{t}}$ is weight of the sample at time $\mathrm{t}$ and $\mathrm{W}_{\infty}$ is the final weight of the sample.

A typical model for a kinetic process can be expressed as:

$$
\frac{\mathrm{d} \alpha}{\mathrm{dt}}=\mathrm{kf}(\alpha)
$$

$\mathrm{d} \alpha / \mathrm{dt}$ is the decomposition rate, $\mathrm{k}$ is the decomposition rate constant and $f(\alpha)$ is the differential expression of a kinetic model function. The temperature dependence of the rate constant $\mathrm{k}$ may be described by the Arrhenius expression

$$
\mathrm{k}=\mathrm{A} \exp \left(\frac{-\mathrm{E}_{\mathrm{a}}}{\mathrm{RT}}\right)
$$

where $\mathrm{A}$ is the pre-exponential factor $(1 / \mathrm{sec})$, assumed to be independent of temperature, $\mathrm{E}_{\mathrm{a}}$ is the activation energy $(\mathrm{kJ} / \mathrm{mol})$, T is the temperature (Kelvin) and $\mathrm{R}$ is the gas constant (8.314 J/mol K).

Combining equations 2 and 3 leads to

$$
\frac{\mathrm{d} \alpha}{\mathrm{dt}}=\mathrm{A} \exp \left(\frac{-\mathrm{E}_{\mathrm{a}}}{\mathrm{RT}}\right) \mathrm{f}(\alpha)
$$

If the sample temperature is increased by a constant heating rate $\beta(\beta=\mathrm{dT} / \mathrm{dt})$ then equation 4 becomes

$$
\frac{\mathrm{d} \alpha}{\mathrm{dT}}=\frac{\mathrm{A}}{\beta} \exp \left(\frac{-\mathrm{E}_{\mathrm{a}}}{\mathrm{RT}}\right) \mathrm{f}(\alpha)
$$

Therefore eqn. 5 is the fundamental relation to determine the kinetic parameters on the basis of $\mathrm{TG}$ data ${ }^{26}$. A number of methods are available in the literature to determine the activation energy however; we will make the use of two wellknown methods.

Flynn-Wall-Ozawa method: Flynn-Wall-Ozawa method $^{27}$ is one of the integral methods used for the estimation of activation energy without having the knowledge of reaction order. This method can be expressed in terms of eqn. 6 :

$$
\log \beta=\log \frac{\mathrm{AE}_{\mathrm{a}}}{\mathrm{g}(\alpha) \mathrm{R}}-2.315-\frac{0.4567 \mathrm{E}_{\mathrm{a}}}{\mathrm{RT}}
$$

Here, $\mathrm{A}$ and $\mathrm{R}$ are constants and for a particular conversion, $\mathrm{g}(\alpha)$ is a constant. The value of $\mathrm{E}_{\mathrm{a}}$ can be obtained from the slope of the curve obtained by plotting $\log \beta$ versus $1 / \mathrm{T}$ for different heating rates for any particular degree of conversion $(\alpha)$.

Coats-Redfern method: Coats-Redfern method ${ }^{28}$ assumes different order of reactions and compares the linearity in each case to select the correct one ${ }^{29}$. The proposed equation is as under:

$$
\log \left[\frac{1-(1-\alpha)^{1-n}}{T^{2}(1-n)}\right]=\log \frac{A R}{\beta E_{a}}\left[1-\frac{2 R T}{E_{a}}\right]-\frac{E_{a}}{2.303 R T} \text { for } n \neq 1
$$

$$
\log \left[\frac{-\log (1-\alpha)}{\mathrm{T}^{2}}\right]=\log \frac{\mathrm{AR}}{\beta \mathrm{E}_{\mathrm{a}}}\left[1-\frac{2 \mathrm{RT}}{\mathrm{E}_{\mathrm{a}}}\right]-\frac{\mathrm{E}_{\mathrm{a}}}{2.303 \mathrm{RT}} \text { for } \mathrm{n}=1
$$

Here $\mathrm{n}$ is the order of reaction. By plotting left hand side of these equations versus $1 / \mathrm{T}$, the slope will be equal to $\mathrm{E}_{\mathrm{a}} / 2.303 \mathrm{R}$ and hence $\mathrm{E}_{\mathrm{a}}$ and $\mathrm{A}$ values can be obtained. It is to be noted that the value of $2 \mathrm{RT} / \mathrm{E}_{\mathrm{a}}$ is considered to be very small $(<<1)$ hence considered as independent of temperature.

Determination of order of reaction: The order of reaction and pre-exponential factor can be obtained using equation $9^{30}$ :

$$
\ln \left[\frac{\frac{\beta d \alpha}{d T}}{\exp \left(-\frac{E_{a}}{R T}\right)}\right]=\ln A+n \ln (1-\alpha)
$$

from the plots of left hand side of eqn. $9 v s . \ln (1-\alpha)$, the order of reaction and the pre-exponential factor can be obtained from the slope and intercept of the plots, respectively ${ }^{26,30,31}$.

\section{RESULTS AND DISCUSSION}

Melt flow index: Melt flow indices (MFI) were measured before the exposure. It was $0.106 \mathrm{~g} / 10 \mathrm{~min}$ and $0.781 \mathrm{~g} / 10$ min for sample $\mathrm{Y}$ and $\mathrm{E}$, respectively. The smaller value of MFI for sample $\mathrm{Y}$ indicated that it was more viscous than sample E under same conditions; thus concluding that the molecular weight of sample $\mathrm{Y}$ was higher than sample E.

Oxidative induction time: The oxidative induction time (OIT) measured prior to exposure was $41.11 \mathrm{~min}$ and 5.33 min for samples $\mathrm{Y}$ and $\mathrm{E}$, respectively. The greater OIT value of sample $\mathrm{Y}$ indicated that it was more thermally stable and hence had more antioxidants to prevent it from oxidation as compared to sample E.

Per cent crystallinity: Both the samples (before, during and after exposing in QUV chamber) were analyzed for per cent crystallinity by DSC and their 1st cycle of temperature scan was taken into account because it contained the thermal history of the samples ${ }^{32}$. It was observed that melting point of both the samples was decreased with the exposure time but the decrease was not noticeable up to 5 days of the exposure time (Fig. 1). However, the decrease was quite sharp for the exposure time from 5 to 16 days for sample $\mathrm{Y}$ and from 5 to 10 days for sample $\mathrm{E}$ and then became constant. It was concluded that the degradation started after 5 days and lasted up to 10 (E) and 16 (Y) days of exposure time. The decrease in melting temperature may likely due to increased crosslinking associated with scission and oxidation reactions ${ }^{33}$. The difference in the trend of the samples was attributed to different thermal stability of the samples due to difference in molecular weight and added antioxidant to the material ${ }^{34}$.

The degree of crystallinity $\left(\mathrm{X}_{\mathrm{cr}}\right)$ was determined according to the following relation:

$$
\mathrm{X}_{\mathrm{cr}}=100 \times\left(\frac{\Delta \mathrm{H}}{\Delta \mathrm{H}_{\mathrm{o}}}\right)
$$

Here $\Delta \mathrm{H}$ is the enthalpy of fusion of the sample obtained from DSC results. The $\Delta \mathrm{H}_{\mathrm{o}}$ was the enthalpy of fusion of $100 \%$ crystalline polyethylene and considered to be equivalent to 


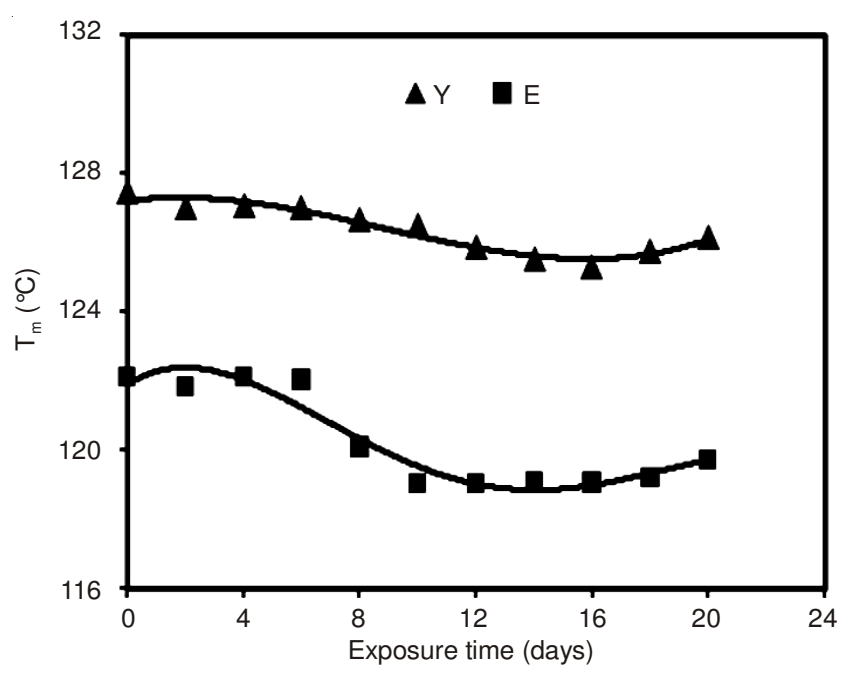

Fig. 1. Melting point as a function of exposure time to accelerated weathering conditions by keeping in QUV chamber

$290 \mathrm{~J} / \mathrm{g}^{35-37}$. The results indicated that the enthalpy was increased from 141.5 to $183.3 \mathrm{~J} / \mathrm{g}$ for sample $\mathrm{Y}$ and 89.7 to $136.6 \mathrm{~J} / \mathrm{g}$ for sample E by the exposure of the material to accelerated weathering conditions. The per cent crystallinity obtained through equation 10 was increased from 48.81 to 63.20 and 30.93 to 47.09 for sample $\mathrm{Y}$ and E, respectively (Fig. 2). The rate for increase in per cent crystallinity up to exposure of 10 days in QUV chamber was 0.495 and 0.082 while after 11 to 20 days of exposure it was increased up to 0.665 and 1.482 for sample $\mathrm{Y}$ and $\mathrm{E}$, respectively. It was obvious that the rate was high for sample E as compared to for sample Y. An increase in crystallinity was attributed to rupturing of long molecular chains (chain scission) and hence the segregation of entangled molecular segments took place which encouraged the re-crystallization process $\mathrm{s}^{38-40}$ and resulted in the decrease in the toughness of the material which made it more brittle and ultimately leads to the degradation of the material ${ }^{33}$. This conclusion was also supported from the fact that the polymer having low molecular mass showed high crystallinity than the polymer having high molecular mass.

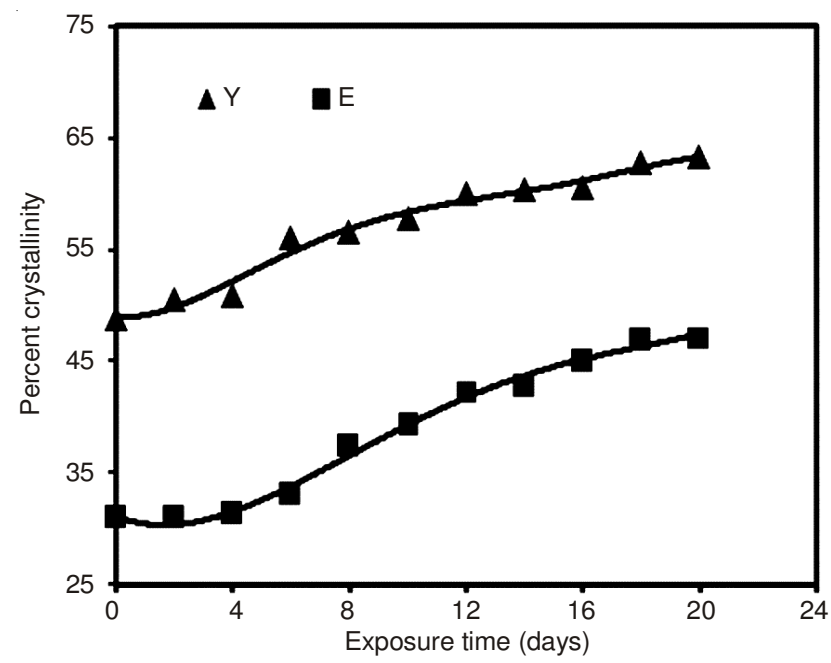

Fig. 2. An increase in present crystallinity of polyethylene samples with the increase in exposure time to accelerated weathering conditions by keeping in QUV chamber
IR results of special Yaadgar sample of Pakistan ( $Y)$ : It has been recognized that the IR spectra of polyethylene in the range $1400-1300 \mathrm{~cm}^{-1}$ can be exploited to identify the type of polyethylene ${ }^{41}$. In case of Y sample, only a single peak in this range $\left(1367 \mathrm{~cm}^{-1}\right)$ was observed (Fig. 3), indicating that the sample was HDPE. In addition to above, peaks at 2360, 2922 and at $2852 \mathrm{~cm}^{-1}$ were observed and were assigned to impurities/additives, $-\left(\mathrm{CH}_{2}\right)_{\mathrm{n}}-\mathrm{C}-\mathrm{H}$ asymmetric and symmetric stretching, respectively (Fig. 4). A combined peak was observed at $1471 \& 1463 \mathrm{~cm}^{-1}$ which was due to $-\left(\mathrm{CH}_{2}\right)_{\mathrm{n}^{-}}$, $\mathrm{C}-\mathrm{H}$ bending. Other combined peaks were noted at 729 and $719 \mathrm{~cm}^{-1}$ assigned to $-\left(\mathrm{CH}_{2}\right)_{\mathrm{n}}$ - rocking vibrations when $\mathrm{n} \geq 3$.

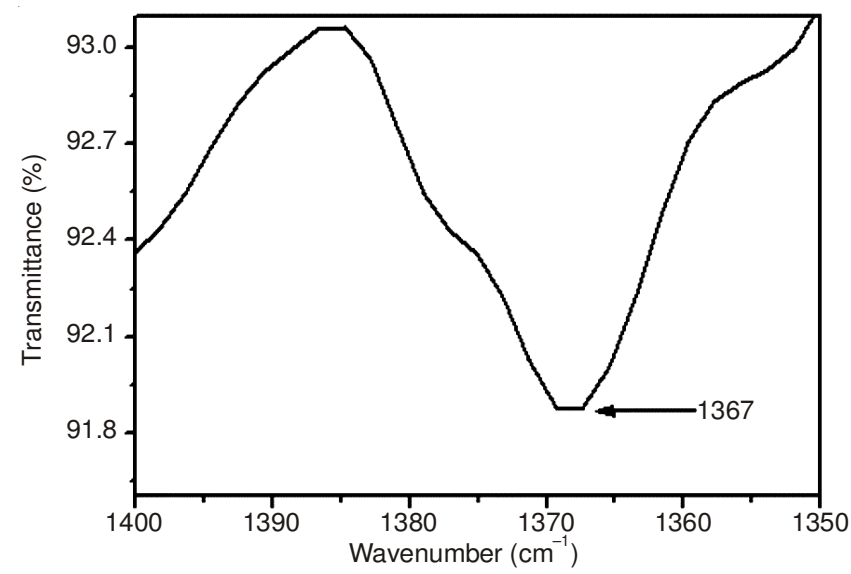

Fig. 3. Before exposure to accelerated weathering conditions the type of sample $\mathrm{Y}$ was HDPE

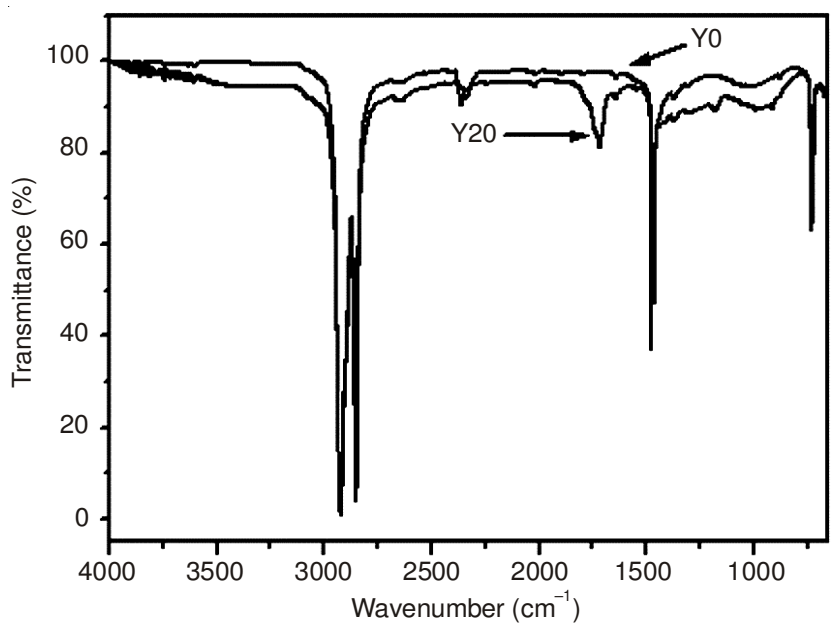

Fig. 4. IR spectra of sample Y, (Y0) before and (Y20) after 20 days exposure time

By exposing the same sample to QUV chamber for 20 days, its IR gave another peak at $1377 \mathrm{~cm}^{-1}$, indicating that the sample was changed to LLDPE (Fig. 5). A peak which was observed at $2360 \mathrm{~cm}^{-1}$ before the exposure was disappeared and a new peak at $1715 \mathrm{~cm}^{-1}$ was observed concluding that the additive might have been volatilized/leached out with the exposure and carbonyl compounds have been formed as depicted in Fig. 4. The formation of carbonyl peak also indicated that the oxidation has taken place due to degradation of the polymer ${ }^{42}$. It was also observed that the intensity of $1715 \mathrm{~cm}^{-1}$ band was gradually increased with the exposure time which confirmed the degradation of material with time. 


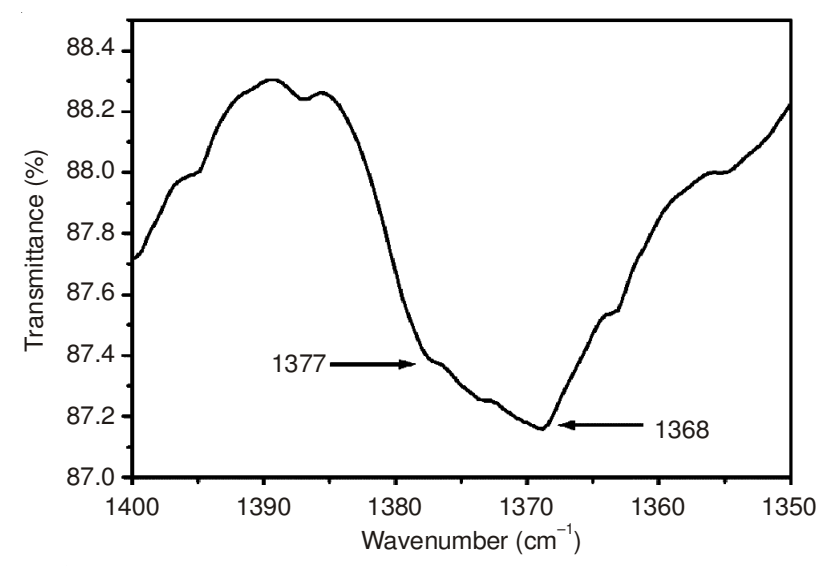

Fig. 5. After exposure to accelerated weathering conditions the type of sample Y was changed from HDPE to LLDPE

IR results for econogreen plastics sample of Canada (E): The IR spectra of the sample E obtained before exposing to accelerated weathering conditions revealed that a peak observed at $1377 \mathrm{~cm}^{-1}$ was weaker than at $1367 \mathrm{~cm}^{-1}$ indicating that the sample was LLDPE ${ }^{41}$ (Fig. 6). In addition, peaks were observed at 2912 and $2847 \mathrm{~cm}^{-1}$ and were assigned to $-\left(\mathrm{CH}_{2}\right)_{\mathrm{n}}-\mathrm{C}-\mathrm{H}$ asymmetric and symmetric stretching, respectively (Fig. 7). A set of two combined peaks observed at 1471-1462 $\mathrm{cm}^{-1}$ and at $729-719 \mathrm{~cm}^{-1}$ were assigned to methylene bending and rocking vibrations, respectively.

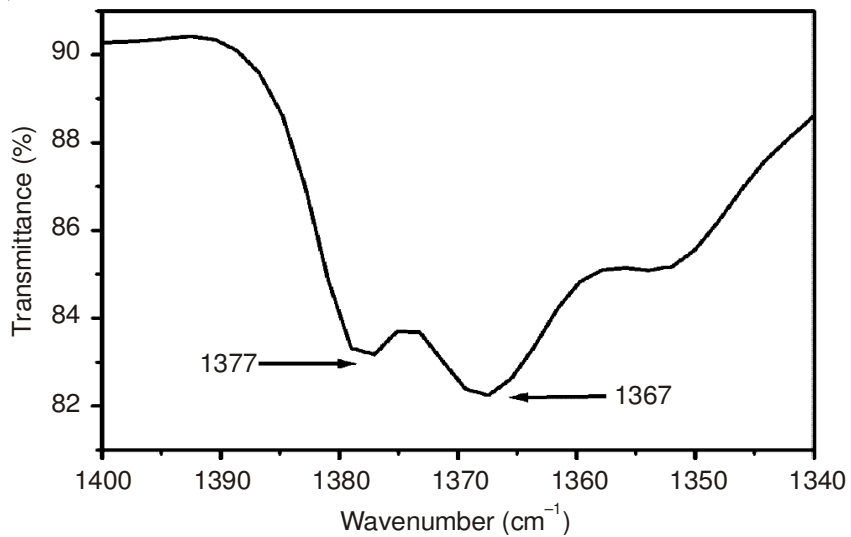

Fig. 6. Before exposure to accelerated weathering conditions the type of sample E was LLDPE

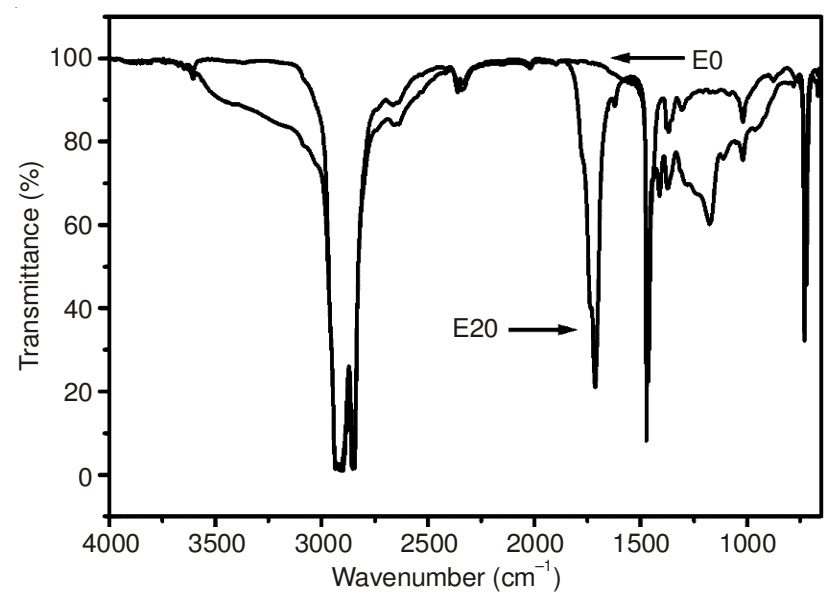

Fig. 7. IR spectra of sample E, (E0) before and (E20) after 20 days of exposure time
By exposing the same sample for 20 days in QUV chamber, it was observed that peak at $1378 \mathrm{~cm}^{-1}$ became stronger than the one observed at $1368 \mathrm{~cm}^{-1}$ reflecting that the sample has been changed from LLDPE to LDPE ${ }^{41}$ (Fig. 8). It can be concluded that the rupturing of long chains of the polymer has been occurred. The peaks observed at $1715 \mathrm{~cm}^{-1}$ indicated the formation of carbonyl compounds like ketones and alde hydes. A peak observed at $1170 \mathrm{~cm}^{-1}$ was attributed to stretching and bending of C-CO-C confirming the presence of ketone ${ }^{43}$ and this peak was also observed in sample $\mathrm{Y}$ after having the exposure of 20 days in QUV chamber which rationalize the formation of ketones as a major oxygenated product in both the samples. It was observed that in case of sample $\mathrm{E}$ the intensity of peaks 1715 and $1170 \mathrm{~cm}^{-1}$ was greater than in sample Y.

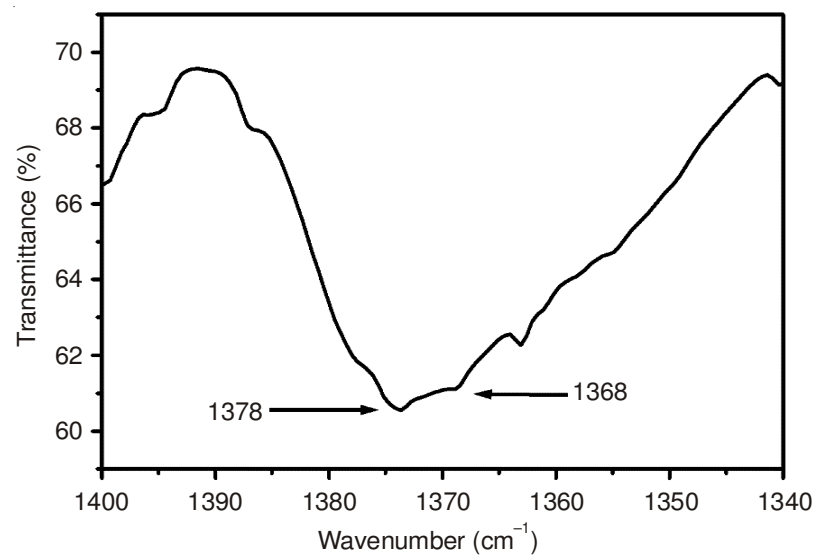

Fig. 8. After exposure to accelerated weathering conditions the type of sample E was changed from LLDPE to LDPE

The rate of formation of carbonyl groups of the samples was calculated in term of carbonyl index (CI) which gave a numerical value and thus the extent of oxidation/degradation was quantified. Carbonyl index was calculated on the basis of the area of the peak $1715 \mathrm{~cm}^{-1}$ and considering $2923 \mathrm{~cm}^{-1}(\mathrm{C}-\mathrm{H}$ stretching) as a reference peak by using equation $11^{44,45}$.

Carbonyl index $=\frac{\left(\text { Area of absorbance at } 1715 \mathrm{~cm}^{-1}\right)}{\left(\text { Area of absorbance at } 2923 \mathrm{~cm}^{-1}\right)} \times 100$

The carbonyl index for Y and E samples was plotted as a function of exposure time in Fig. 9. The results indicated that CI was increased with the exposure time ${ }^{25}$ and the rate of formation was high for sample E as compared to Y, throughout the experiment. The difference in the CI between two samples was accredited to the disparity in degree of polydispersity, molecular weight, viscosity and effectiveness of antioxidants against thermo-oxidation process of the two samples. This hypothesis is also supported by high OIT and low MFI of sample Y. The stated observations/facts concluded that the photodegradation and thermal degradation occurred by the exposure of the samples to accelerated weathering conditions results in the formation of oxygenated products in both the samples. It is also reported ${ }^{24}$ that the number of oxygenated groups formed during QUV exposure are twice that formed during weather-O-meter exposure and the reason can be explained in terms of irradiance of fluorescent bulbs used in QUV chamber which produce energy equivalent to the dissociation of the $\mathrm{C}-\mathrm{C}$ and $\mathrm{C}-\mathrm{H}$ bonds. 


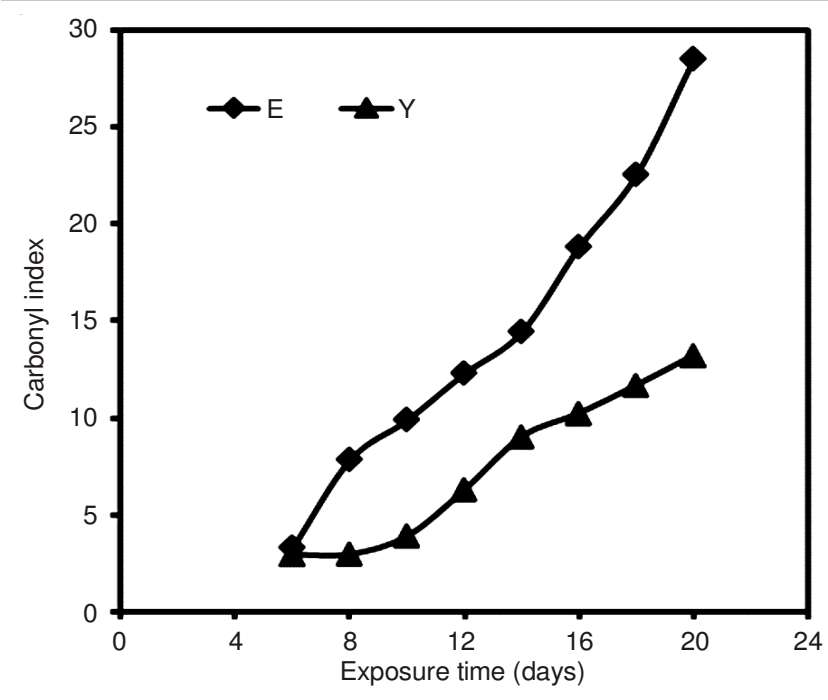

Fig. 9. Carbonyl index as a function of exposure time

SEM analyses: The SEM micrographs obtained for $\mathrm{Y}$ samples after the exposure of 6, 10, 14 and 18 days in QUV chamber are displayed in Fig. 10. Figure showed that with the exposure of the material the peeling process was initiated and preferential sites were then created. These sites further grew up to form cracks and fractures which became deeper and deeper with the exposure time. Ultimately, the process lead to the formation of small pits/depressions which ended up to completely degraded material.

The SEM micrographs of sample E obtained after the exposure in QUV chamber for 2, 6, 10 and 16 days are shown in Fig. 11. The figure illustrated that the process of degradation was different as compared to sample $\mathrm{Y}$ as some flakes and grooves were observed and the initiation of degradation was quite high. The SEM indicates that the degradation was investigated only from the preferential sites in sample $\mathrm{Y}$ and this was because of high concentration of photostabilizers. Whereas, in sample E, the degradation proceeded in all directions and was attributed to the presence of higher concentration of photodegradable materials than sample Y, which were widely distributed and caused the polymer degradation fast. It meant that sample E was less stable and was more conductive to oxidative degradation process than sample Y. This statement is also supported by low OIT, high MFI and high CI values of sample E than the sample Y.

Thermogravimetric analyses: A Thermogravimetric analysis is one of the best techniques for the determination of activation energy and order of reaction during the thermal degradation of the material. In this study, we have employed Flynn-Wall-Ozawa and Coats-Redfern methods and eqns. 6, 7 and 8 were used for the evaluation of activation energy $\left(E_{a}\right)$, before and after exposing the samples to accelerated weathering conditions. The activation energy of both the samples obtained as a function of degree of conversion $(\alpha)$ and its mean value was noted to decrease from 179.13 to 71.31 and 423.64 to $137.68 \mathrm{~kJ} / \mathrm{mol}$ for sample $\mathrm{Y}$ and $\mathrm{E}$, respectively and the results are given in Table-1. A significant decrease in $\mathrm{E}_{\mathrm{a}}$ identifies that the material was degraded to various size of molecules during the exposure. Thermograms of sample $\mathrm{Y}$ and $\mathrm{E}$ at heating rate of $10^{\circ} \mathrm{C} / \mathrm{min}$ before and after the exposure for 20 days in QUV chamber are shown in Fig. 12. It is obvious from the thermograms that before exposure the degradation was occurred at higher temperature while after exposure these curves were shifted back and the process of degradation was
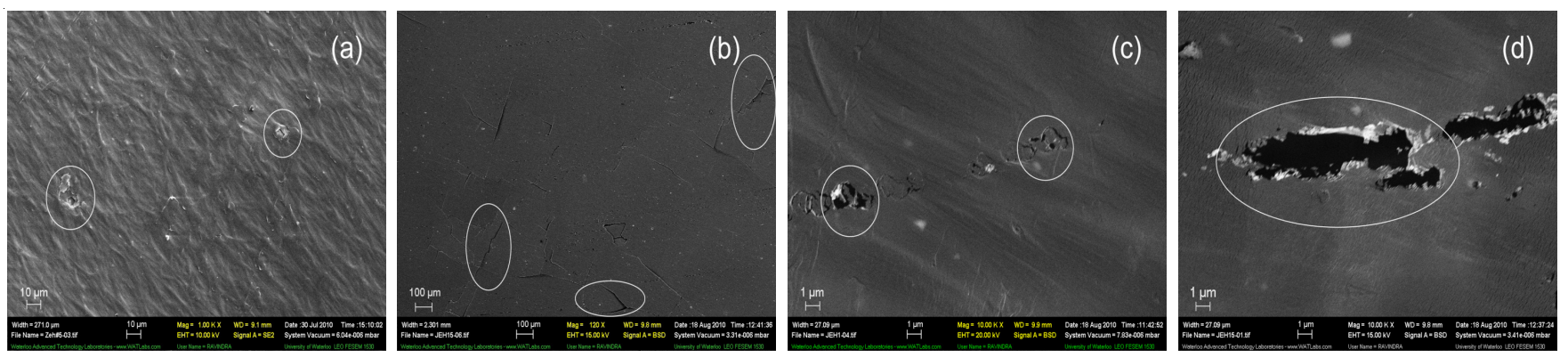

Fig. 10. SEM micrographs of Y samples: (a) sample exposed in QUV chamber for 6 days. The encircled segments indicate the starting of peeling process and these sites may be termed as early preferential degradation sites, (b) Sample exposed for 10 days. The encircled segments indicate the advancement of degradation/oxidation process in terms of cracks/fractures in the sample, (c) The sample exposed for 14 days. The formation of small pits/depressions is very much visible and some of these are enclosed in the circle, (d) The sample exposed for 18 days and the film seems to be tearing up
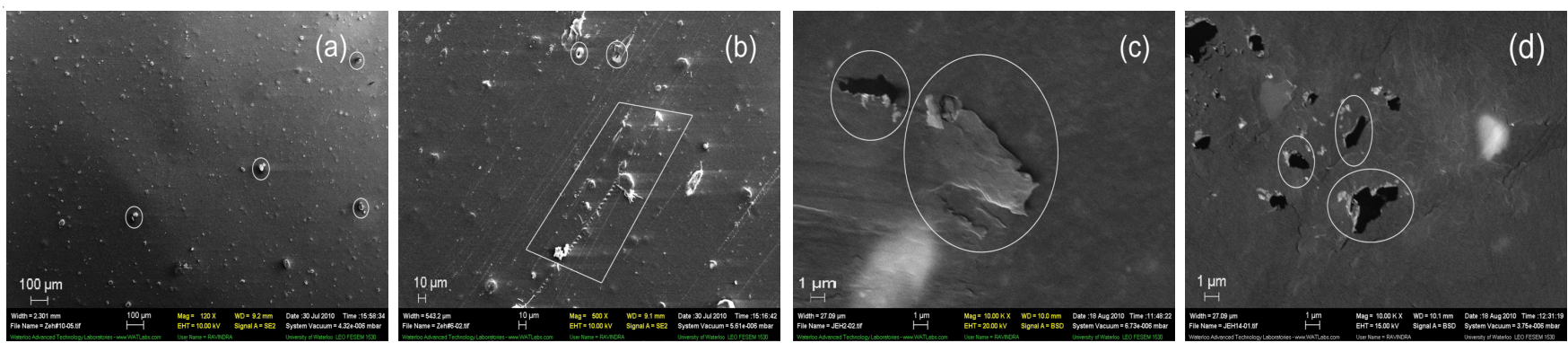

Fig. 11. SEM micrographs of sample E are shown as a, b, c and d which were taken after the exposure in QUV chamber for 2, 6, 10 and 16 days, respectively, (a) The early degradation sites are numerous which reflects the high concentration of photodegradable materials which were broadly distributed all over the sample while encircled segments indicated the etching process, (b) With the passage of time, the propagation of horizontal notching in grooves was observed (rectangular), (c) Peeling/flaking was noticed on the polymer surface, (d) Ultimately the polymer was completely degraded (encircled) while peeling was also observed on rest of the polymer surface 
observed at lower temperature. Before exposure the onset temperature for sample $\mathrm{Y}$ was $448^{\circ} \mathrm{C}$ (with $9 \%$ loss in sample mass) while after exposure it was decreased to $364{ }^{\circ} \mathrm{C}$ (with $11.5 \%$ loss in sample mass) similarly the onset temperature for sample E before the exposure was $431{ }^{\circ} \mathrm{C}$ (with $8 \%$ loss in sample mass) and after having exposure which was decreased to $354{ }^{\circ} \mathrm{C}$ (with $12 \%$ loss in sample mass). From these results it can be concluded that the sample $\mathrm{Y}$ is more thermally stable than the sample $\mathrm{E}$ and further, the drop in $\mathrm{E}_{\mathrm{a}}$ for sample $\mathrm{E}$ was more than sample $\mathrm{Y}$ indicating high degree of degradation in sample E. This conclusion is also in accord with the results of MFI, CI and SEM analysis.

\begin{tabular}{|c|c|c|c|c|}
\hline \multicolumn{5}{|c|}{$\begin{array}{c}\text { TABLE-1 } \\
\text { ACTIVATION ENERGY DETERMINED BY FLYNN-WALL- } \\
\text { OZAWA METHOD IN kJ/mol OF POLYETHYLENE } \\
\text { SAMPLES E AND Y BEFORE AND AFTER EXPOSURE } \\
\text { OF } 20 \text { DAYS IN QUV CHAMBER }\end{array}$} \\
\hline \multirow{2}{*}{$\begin{array}{l}\text { Degree of } \\
\text { conversion } \\
(\alpha)\end{array}$} & \multicolumn{2}{|c|}{$\mathrm{E}_{\mathrm{a}}$ of Y sample $(\mathrm{kJ} / \mathrm{mol})$} & \multicolumn{2}{|c|}{$\mathrm{E}_{\mathrm{a}}$ of E sample $(\mathrm{kJ} / \mathrm{mol})$} \\
\hline & $\begin{array}{c}\text { Before } \\
\text { exposure }\end{array}$ & $\begin{array}{c}\text { After } \\
\text { exposure }\end{array}$ & $\begin{array}{c}\text { Before } \\
\text { exposure }\end{array}$ & $\begin{array}{c}\text { After } \\
\text { exposure }\end{array}$ \\
\hline 0.1 & 158.47 & -57.73 & 356.63 & -59.38 \\
\hline 0.2 & 164.75 & -94.64 & 648.99 & -93.44 \\
\hline 0.3 & 171.25 & -153.23 & 549.41 & -72.64 \\
\hline 0.4 & 174.64 & -213.54 & 472.22 & 122.97 \\
\hline 0.5 & 180.48 & -151.53 & 419.43 & 328.23 \\
\hline 0.6 & 184.23 & 344.06 & 381.93 & 365.73 \\
\hline 0.7 & 188.78 & 471.50 & 350.44 & 306.44 \\
\hline 0.8 & 191.88 & 342.24 & 326.95 & 239.94 \\
\hline 0.9 & 197.70 & 154.65 & 306.74 & 101.16 \\
\hline Mean $E_{a}$ & 179.13 & 71.31 & 423.64 & 137.68 \\
\hline
\end{tabular}

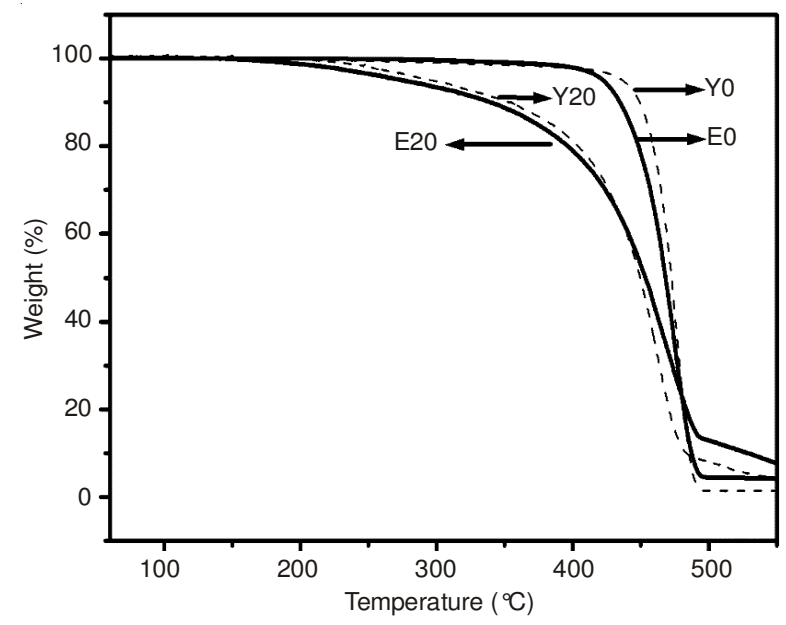

Fig. 12. Thermogram of sample $\mathrm{E}$ and $\mathrm{Y}$ at heating rate of $10^{\circ} \mathrm{C} / \mathrm{min}$. E0, Y0 and E20, Y20 represent before and after the exposure of 20 days in QUV chamber, respectively

The $\mathrm{E}_{\mathrm{a}}$ of the samples was also determined by CoatsRedfern method using eqns. 7 and 8 considering $\mathrm{n} \neq 1$ and $\mathrm{n}=$ 1 as explained in experimental section. $\mathrm{E}_{\mathrm{a}}$ determined by this method for the samples $\mathrm{Y}$ and $\mathrm{E}$ are listed in Tables 2 and 3, respectively. The mean values of $\mathrm{E}_{\mathrm{a}}$ displayed a similar trend as discussed in case of Flynn-Wall-Ozawa method. The $\mathrm{E}_{\mathrm{a}}$ values obtained by Flynn-Wall-Ozawa method for the sample exposed to accelerated weathering conditions were negative for some degree of conversion $(\alpha)$ for both the samples. It can be concluded that the thermal stability of both the samples

\begin{tabular}{|c|c|c|c|c|c|c|}
\hline \multicolumn{7}{|c|}{$\begin{array}{c}\text { TABLE-2 } \\
\text { ACTIVATION ENERGY OF POLYETHYLENE SAMPLE } \\
\text { Y IN kJ/mol DETERMINED BY COATS-REDFERN } \\
\text { METHOD BEFORE AND AFTER EXPOSURE } \\
\text { OF 20 DAYS IN QUV CHAMBER }\end{array}$} \\
\hline \multirow{2}{*}{$\mathrm{n}$} & \multirow{2}{*}{$\begin{array}{c}\mathrm{E}_{\mathrm{a}} \\
(\mathrm{kJ} / \mathrm{mol})\end{array}$} & \multicolumn{4}{|c|}{ Heating rate $\left({ }^{\circ} \mathrm{C} / \mathrm{min}\right)$} & \multirow{2}{*}{ Mean $\mathrm{E}_{2}$} \\
\hline & & 5 & 10 & 15 & 20 & \\
\hline \multirow[t]{2}{*}{0} & $\begin{array}{c}\text { Before } \\
\text { exposure }\end{array}$ & 240.49 & 273.42 & 295.06 & 295.06 & 276.00 \\
\hline & $\begin{array}{c}\text { After } \\
\text { exposure }\end{array}$ & 140.37 & 60.01 & 42.37 & 47.18 & 72.48 \\
\hline \multirow[t]{2}{*}{$1 / 2$} & $\begin{array}{l}\text { Before } \\
\text { exposure }\end{array}$ & 283.38 & 321.67 & 346.75 & 346.94 & 324.69 \\
\hline & $\begin{array}{c}\text { After } \\
\text { exposure }\end{array}$ & 164.38 & 71.00 & 51.16 & 56.37 & 85.73 \\
\hline \multirow[t]{2}{*}{$2 / 3$} & $\begin{array}{c}\text { Before } \\
\text { exposure }\end{array}$ & 299.65 & 340.05 & 366.48 & 366.67 & 343.21 \\
\hline & $\begin{array}{c}\text { After } \\
\text { exposure }\end{array}$ & 173.47 & 75.15 & 54.51 & 59.85 & 90.75 \\
\hline \multirow[t]{2}{*}{1} & $\begin{array}{c}\text { Before } \\
\text { exposure }\end{array}$ & 335.27 & 380.26 & 409.37 & 409.75 & 383.66 \\
\hline & $\begin{array}{c}\text { After } \\
\text { exposure }\end{array}$ & 193.19 & 84.21 & 61.83 & 67.44 & 101.67 \\
\hline
\end{tabular}

TABLE-3

ACTIVATION ENERGY OF POLYETHYLENE SAMPLE E IN

$\mathrm{kJ} / \mathrm{mol}$ DETERMINED BY COATS-REDFERN METHOD BEFORE AND AFTER EXPOSURE OF 20 DAYS IN QUV CHAMBER

\begin{tabular}{|c|c|c|c|c|c|c|}
\hline \multirow{2}{*}{$\mathrm{n}$} & \multirow{2}{*}{$\mathrm{E}_{\mathrm{a}}(\mathrm{kJ} / \mathrm{mol})$} & \multicolumn{4}{|c|}{ Heating rate } & \multirow{2}{*}{ Mean $E_{a}$} \\
\hline & & 5 & 10 & 15 & 20 & \\
\hline \multirow[t]{2}{*}{0} & $\begin{array}{c}\text { Before } \\
\text { exposure }\end{array}$ & 244.32 & $\begin{array}{c}179.8 \\
5\end{array}$ & 166.20 & 169.64 & 190.00 \\
\hline & $\begin{array}{c}\text { After } \\
\text { exposure }\end{array}$ & 109.58 & 41.45 & 51.49 & 41.84 & 61.09 \\
\hline \multirow[t]{2}{*}{$1 / 2$} & $\begin{array}{c}\text { Before } \\
\text { exposure }\end{array}$ & 288.16 & $\begin{array}{c}212.1 \\
5\end{array}$ & 196.26 & 200.47 & 224.26 \\
\hline & $\begin{array}{c}\text { After } \\
\text { exposure }\end{array}$ & 128.53 & 50.15 & 61.46 & 50.43 & 72.64 \\
\hline \multirow[t]{2}{*}{$2 / 3$} & $\begin{array}{c}\text { Before } \\
\text { exposure }\end{array}$ & 304.82 & $\begin{array}{c}224.4 \\
0\end{array}$ & 207.74 & 212.15 & 237.28 \\
\hline & $\begin{array}{c}\text { After } \\
\text { exposure }\end{array}$ & 135.70 & 53.46 & 65.23 & 53.70 & 77.02 \\
\hline \multirow[t]{2}{*}{1} & $\begin{array}{l}\text { Before } \\
\text { exposure }\end{array}$ & 341.59 & $\begin{array}{c}251.4 \\
0\end{array}$ & 232.83 & 238.00 & 265.95 \\
\hline & $\begin{array}{c}\text { After } \\
\text { exposure }\end{array}$ & 151.36 & 60.72 & 73.50 & 60.85 & 86.61 \\
\hline
\end{tabular}

was reduced and the composition of the material was changed which facilitated the degradation process. Coats-Redfern method was used to determine the $\mathrm{E}_{\mathrm{a}}$ while assuming $\mathrm{n}$ equal to $0,1 / 2,2 / 3$ and 1 . The exposure of both the samples lowered the $E_{a}$ for both the samples, this means that the exposures resulted in rupturing of bonds.

Determination of order of reaction: For the estimation of order of reaction, the results were plotted according to eqn. 9 as depicted in Fig. 13. The order of thermal degradation for both the samples obtained in this way was 1.057 and 0.931 for sample $\mathrm{Y}$ and 1.050 and 0.717 for sample $\mathrm{E}$ before and after the exposure, respectively. The decrease in order of reaction due to exposure was greater for sample E than sample Y and attributed to formation of some smaller molecular weight species and some active radicals in the sample.

Thermal stability: The thermal stability of both the samples was assessed with the help of TGA before and after exposing the samples to accelerated weathering conditions for 


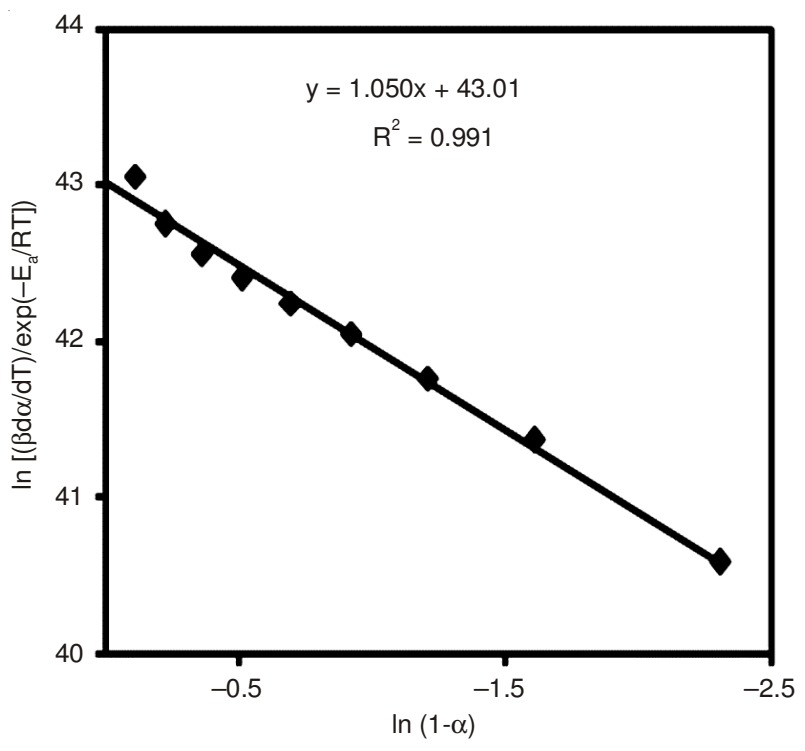

Fig. 13. Thermal degradation of sample E, measured at heating rate of 20 ${ }^{\circ} \mathrm{C} / \mathrm{min}$ and before keeping in QUV chamber. The data has been plotted according to equation 9 for the calculation of order of reaction

20 days. The results indicated that $10 \%$ conversion (thermal degradation) took place at 422 and $382{ }^{\circ} \mathrm{C}$, before and after the exposure for sample $\mathrm{E}$, respectively; concluding that the material became thermally unstable and needed low temperature to degrade. Similar trend was observed for sample Y. The per cent decrease in the temperature required for conversion up to $10 \%(\alpha=0.1)$ was calculated using eqn. 12 and displayed in Fig. 14.

$$
\text { Per cent decrease in temperature }=\frac{\left(T_{b}-T_{e}\right)}{T_{b}} \times 100
$$

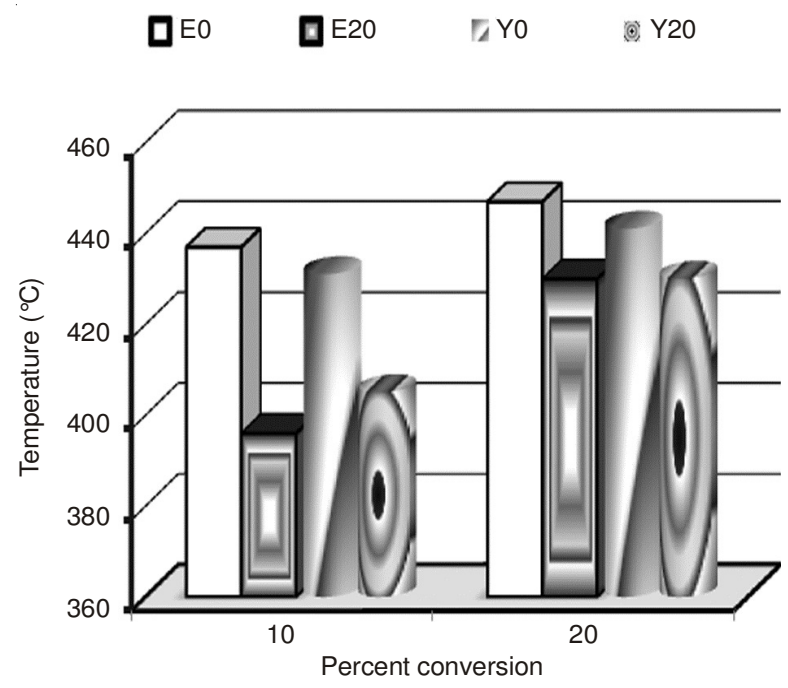

Fig. 14. Degradation temperatures noted at 10 and 20 per cent conversion for the samples E and Y before (E0, Y0) and after (E20, Y20) the exposure of 20 days in QUV chamber

$\mathrm{T}_{\mathrm{b}}$ and $\mathrm{T}_{\mathrm{e}}$ represent the temperatures before and after the exposure, respectively at the degradation level of $10 \%$. The per cent decrease in temperature for sample E (9.38) was greater than the sample Y (6.03), reflecting that the sample E was more vulnerable to thermal/photo-oxidation. This statement was also supported by the pronounced cracks which were observed with the naked eye in the film of sample $\mathrm{E}$ with the exposure to accelerated weathering conditions (Fig. 15). In our case, this was the reasons that up to 20 days of exposure in QUV chamber under the prevailing conditions both the samples were degraded into small particles and were unable to be mounted on the samples holders of the QUV chamber for further exposure. All these results indicated that the sample Y was more stable than sample E against heat as well as UV light. The $\mathrm{E}_{\mathrm{a}}$ values were low for sample $\mathrm{E}$ and hence it was degraded with high rate. The reason behind this difference was due to high molecular weight, greater OIT, low percent crystallinity and low value of carbonyl index of sample $\mathrm{Y}$ as compared to sample E.

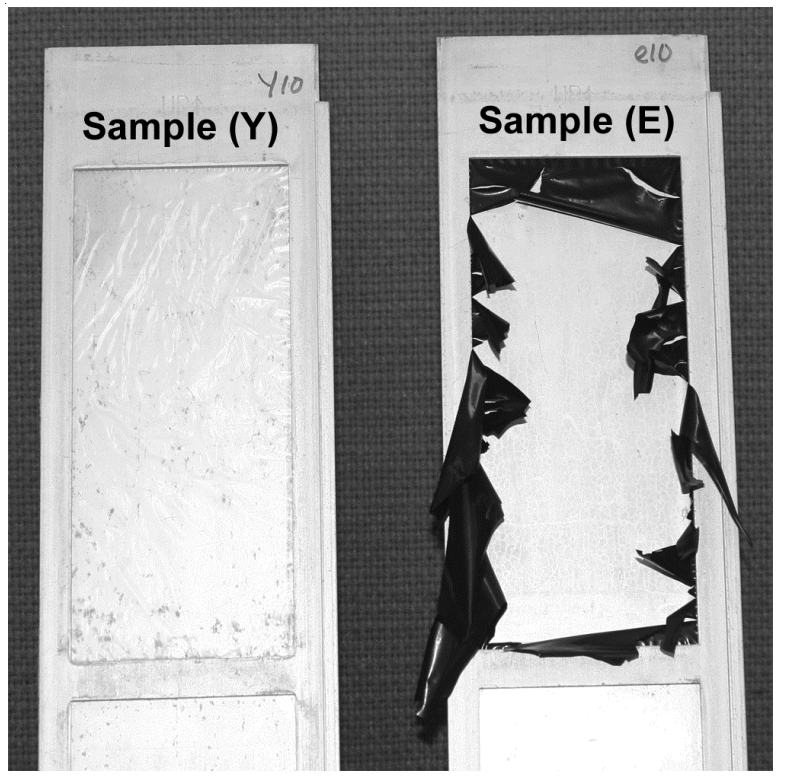

Fig. 15. Photographs of polyethylene films of sample $\mathrm{Y}$ (dim colour) and sample E (black) after exposing to AWC in QUV chamber

\section{Conclusion}

The impacts of weathering conditions over the thermal stability, degradation kinetics and morphology have been investigated. The study concludes that when both the polyethylene samples were exposed to accelerated weathering conditions by keeping the samples in QUV chamber for 20 days under the prevailing conditions, they were degraded into fine pieces. The following most important observations were made. Sample Y was changed from HDPE to LLDPE while sample E from LLDPE to LDPE. The rate of formation of oxygenated products in terms of carbonyl index was high for sample $E$ as compared to sample Y. The percent crystallinity was increased while melting point of both the samples was decreased. Thermal stability, order of reaction and activation energy determined by Flynn-Wall-Ozawa and Coats-Redfern methods was decreased. SEM analyses revealed that the degradation was investigated only from the preferential sites in sample $\mathrm{Y}$ which reflected the high contents of photostabilizers. In case of sample $E$ the degradation proceeded in all the directions and was attributed to the presence of high contents of photodegradable material rather than photostabilizers. 
Finally, it is suggested that the impact of accelerated weathering conditions on sample $\mathrm{E}$ was greater as compared to sample Y and was attributed to its low molecular weight, low viscosity and smaller amount of antioxidant in sample E as compared to sample $\mathrm{Y}$, which made the sample E thermally unstable and more vulnerable to thermal/photo-oxidative degradation.

\section{ACKNOWLEDGEMENTS}

One of the authors (Malik Jehanzeb Khurram) are highly obliged to the Higher Education Commission of Pakistan for providing the financial assistance and also grateful to Prof. Dr. Leonardo C. Simon for his precious guidance and granting permission to use state-of-the-art laboratories and instrumentation available at University of Waterloo, Ontario, Canada, for the achievement of this research work.

\section{REFERENCES}

1. T.O. Kumanayaka, R. Parthasarathy and M. Jollands, Polym. Degrad. Stab., 95, 672 (2010).

2. B. Singh and N. Sharma, Polym. Degrad. Stab., 93, 561 (2008).

3. G. Kämpf, K. Sommer and E. Zirngiebl, Prog. Org. Coat., 19, 69 (1991).

4. T. Kuroki, T. Sawaguchi, S. Niikuni and T. Ikemura, Macromolecules, 15, 1460 (1982).

5. M.A. Salem, H. Farouk and I. Kashif, Macromol. Res, 10, 168 (2002).

6. A. Aboulkas, K. El Harfi and A. El Bouadili, Energy Convers. Manage., 51, 1363 (2010).

7. Y.S. González, C. Costa, M.C. Márquez and P. Ramos, J. Hazard. Mater., 187, 101 (2011).

8. S. Djellali, N. Haddaoui, T. Sadoun, A. Bergeret and Y. Grohens, Iran Polym. J., 22, 245 (2013).

9. X. Zhao, Z. Li, Y. Chen, L. Shi and Y. Zhu, J. Mol. Catal. Chem., 268, 101 (2007).

10. M. Azhar Uddin, Y. Sakata, A. Muto, Y. Shiraga, K. Koizumi, Y. Kanada and K. Murata, Micropor. Mesopor. Mater., 121, 557 (1998).

11. D. Dong, S. Tasaka and N. Inagaki, Polym. Degrad. Stab., 72, 345 (2001).

12. G. Swift, in ed.: J.E. Glass, Agricultural and Synthetic Polymers: Biodegradation and Utilization; ACS Symposium Series 433; American Chemical Society: Washington, DC, p. 198 (1990).

13. A.L. Andrady, H.S. Hamid and A. Torikai, Photochem. Photobiol. Sci., 2, 68 (2003).

14. F. Cataldo, Polym. Degrad. Stab., 72, 287 (2001).
15. S.H. Hamid and M.B. Amin, J. Appl. Polym. Sci., 55, 1385 (1995).

16. T.J. Kemp and R.A. McIntyre, Polym. Degrad. Stab., 91, 3020 (2006).

17. A.C. Albertsson, S.O. Andersson and S. Karlsson, Polym. Degrad. Stab., 18, 73 (1987).

18. A.C. Albertsson and S. Karlsson, Acta Polym., 46, 114 (1995).

19. D. Feldman, J. Polym. Environ., 10, 163 (2002).

20. S. Banisadr and H. Asempour, Iran Polym. J., 21, 463 (2012).

21. J.V. Gulmine, P.R. Janissek, H.M. Heise and L. Akcelrud, Polym. Degrad. Stabil., 79, 385 (2003).

22. L. Zhou, T. Luo and Q. Huang, Energy Convers. Manage., 50, 705 (2009).

23. A. Aboulkas, K. El Harfi and A. El Bouadili, Energy Convers. Manage., 49, 3666 (2008).

24. J.V. Gulmine and L. Akcelrud, Polym. Test., 25, 932 (2006),

25. C.S. Li, M.S. Zhan, X.C. Huang and H. Zhou, Polym. Test., 31, 938 (2012).

26. X. Meng, Y. Huang, H. Yu and Z. Lv, Polym. Degrad. Stab., 92, 962 (2007).

27. M. Rakhshani, M.M. Kamrannejad, A.A. Babaluo, M. Rezaei and M.R. Aghjeh, Iran Polym. J., 21, 821 (2012).

28. A.W. Coats and J.P. Redfern, Nature, 201, 68 (1964).

29. D.W. Johnson and P.K. Gallagher, J. Phys. Chem., 76, 1474 (1972).

30. M.K. Baloch, M.J. Khurram and G.F. Durrani, J. Appl. Polym. Sci., 120, 3511 (2011).

31. A.C. Lua and J. Su, Polym. Degrad. Stab., 91, 144 (2006).

32. M.F.S. Lima, M.A.Z. Vasconcellos and D. Samios, J. Polym. Sci., B, Polym. Phys., 40, 896 (2002).

33. A.L. dos Santos Alves, L.F. Cassiano Nascimento and J.C.M. Suarez, Polym. Test., 24, 104 (2005).

34. A. Larena, S. Jiménez de Ochoa and F. Domínguez, Polym. Degrad. Stabil., 91, 940 (2006).

35. G. Sarkhel and A. Choudhury, J. Appl. Polym. Sci., 115, 376 (2010).

36. W. Lin, M. Cossar, V. Dang and J. Teh, Polym. Test., 26, 814 (2007).

37. S. Dalai and C. Wenxiu, J. Appl. Polym. Sci., 86, 553 (2002).

38. M.S. Rabello and J.R. White, Polym. Degrad. Stab., 56, 55 (1997).

39. D. Dudic, D. Kostoski, V. Djokovic and Z. Stojanovic, Polym. Degrad. Stabil., 67, 233 (2000).

40. M. Obadal, R. Cermák, M. Raab, V. Verney, S. Commereuc and F. Fraïsse, Polym. Degrad. Stab., 91, 459 (2006).

41. J.V. Gulmine, P.R. Janissek, H.M. Heise and L. Akcelrud, Polym. Test., 21, 557 (2002).

42. E. Chiellini, A. Corti, S. D'Antone and R. Baciu, Polym. Degrad. Stab., 91, 2739 (2006).

43. B.K. Sharma, Spectroscopy, Goel Publishing House, India, p. 299 (2007).

44. F.G.D. Ferreira, M.A.G.A. Lima, Y.M.B. Almeida and G.M. Vinhas, Polímeros., 19, 313 (2009).

45. L. Amato, M. Gilbert and A. Caswell, Plast Rubber Compos., 34, 171 (2005). 